\title{
Heterogeneous oxidation of carbonyl sulfide on mineral oxides
}

\author{
LIU YongChun, LIU JunFeng, HE Hong ${ }^{\dagger}$, YU YunBo \& XUE Li \\ Research Center for Eco-Environmental Science, Chinese Academy of Sciences, Beijing 100085, China
}

Heterogeneous oxidation of carbonyl sulfide (OCS) on mineral oxides including $\mathrm{SiO}_{2}, \mathrm{Fe}_{2} \mathrm{O}_{3}, \mathrm{CaO}, \mathrm{MgO}$, $\mathrm{ZnO}$ and $\mathrm{TiO}_{2}$, which are the main components of atmospheric particles, were investigated using in situ diffuse reflectance infrared Fourier transform spectroscopy (in situ DRIFTS), ion chromatography (IC), temperature-programmed desorption (TPD), X-ray diffraction (XRD) and Brunauer-Emmett-Teller (BET) methods. The main products and intermediates of the heterogeneous oxidation of OCS on these oxides were identified with in situ DRIFTS and IC. The reaction mechanism and kinetics were also discussed. It is found that the reaction mechanism on these mineral oxides is the same as that on $\mathrm{Al}_{2} \mathrm{O}_{3}$ for the same final products and the intermediates at room temperature. Namely, OCS can be catalytically oxidized to produce surface $\mathrm{SO}_{4}^{2-}$ species and gaseous $\mathrm{CO}_{2}$ through the surface hydrogen thiocarbonate $\left(\mathrm{HSCO}_{2}^{-}\right)$ and $\mathrm{HSO}_{3}^{-}$species. The activity series for heterogeneous oxidation of OCS follows: $\mathrm{Al}_{2} \mathrm{O}_{3} \approx \mathrm{CaO}>\mathrm{MgO}$ $>\mathrm{TiO}_{2} \approx \mathrm{ZnO}>\mathrm{Fe}_{2} \mathrm{O}_{3}>\mathrm{SiO}_{2}$. The specific area, basic hydroxyl and surface basicity of these oxides have effect on the reactivity. This study suggests that heterogeneous reactions of OCS on mineral dust may be an unneglectable sink of OCS.

carbonyl sulfide, mineral oxides, sulfate, heterogeneous reaction, in situ DRIFTS

Carbonyl sulfide (OCS) is one of the most abundant sulfur containing species in the atmosphere. It is relatively inert in the troposphere ${ }^{[1,2]}$ and can be transported into stratosphere, where its photolysis is the important source of stratospheric sulfate aerosol ${ }^{[1-4]}$. It has been deduced by Crutzen ${ }^{[3]}$ that OCS contributes to the stratospheric sulfate aerosol during volcanically quiescent periods. Sulfate aerosol has an important influence on the visibility in the low troposphere, the Earth's radiation balance and global climate as well as stratospheric ozone chemistry ${ }^{[1-3,5,6]}$. Therefore, much attention has been given to the sources and sinks of OCS.

According to the estimation of Watts in 2000, there exists a large discrepancy between the known sources and sinks of OCS $^{[4]}$. This suggests there may be an uncertainty for sources or sinks of OCS. In recent years, the heterogeneous reaction on atmospheric particles in troposphere has attracted much interest due to its significant effect on the formation of ozone hole and the cycles of nitrogen and sulfur in the atmosphere ${ }^{[7]}$. On the other hand, the ubiquitous atmospheric particles have a large specific surface area. It is not only the support for pollutants in the course of transportation but also the supplier of reactive surface for atmospheric chemistry ${ }^{[8]}$. The arid and semi-arid areas of China are important source areas of mineral oxides in the world ${ }^{[9]}$. Atmospheric particles originating from soil dust, road dust, sea salts, etc. consist of oxides of silicon, aluminum and calcium, etc. ${ }^{[10,11]}$. The surface hydroxyl ${ }^{[12]}$ or active oxygen species formed by adsorption of gaseous water or oxygen on the mineral oxides may be taken as the reactive sites for heterogeneous reactions of OCS to affect its sinks. On the other hand, it is helpful to under-

\footnotetext{
Received September 7, 2006; accepted February 5, 2007 doi: 10.1007/s11434-007-0281-2

†Corresponding author (email: Honghe@rcees.ac.cn)

Supported by the Ministry of Science and Technology of China (Grant No. 2007CB407301) and the National Natural Science Foundation of China (Grant No. 20637001)
} 
standing the transformation and the fate of trace gases to investigate the heterogeneous reaction on particles ${ }^{[13]}$.

Unfortunately, little is known about the heterogeneous reactions of OCS on mineral oxides and authentic atmospheric particles. Wu et al. ${ }^{[14]}$ have reported the reaction mechanism of OCS on typical components of atmospheric aerosols with Fourier transform infrared spectroscopy (FTIR) and X-ray photoelectron spectrograph (XPS). $\mathrm{CO}_{2}(\mathrm{~g}), \mathrm{S}(\mathrm{s})$ and $\mathrm{SO}_{4}^{2-}$ (s) were identified as gaseous and surface products, respectively. In our previous work, the reaction mechanism of OCS on $\mathrm{Al}_{2} \mathrm{O}_{3}$ was investigated in detail ${ }^{[15]}$. At ambient temperature, hydrogen thiocarbonate $\left(\mathrm{HSCO}_{2}^{-}\right)$was found to be a key intermediate formed by the reaction of OCS with surface hydroxyl. $\mathrm{HSO}_{3}^{-}$(s), $\mathrm{SO}_{4}^{2-}$ (s) and $\mathrm{CO}_{2}$ (g) were also identified with in situ diffuse reflectance infrared Fourier transform spectroscopy (in situ DRIFTS). In this study, $\mathrm{SiO}_{2}, \mathrm{Fe}_{2} \mathrm{O}_{3}, \mathrm{CaO}, \mathrm{MgO}, \mathrm{ZnO}$, $\mathrm{TiO}_{2}, \alpha-\mathrm{Al}_{2} \mathrm{O}_{3}$ and $\gamma-\mathrm{Al}_{2} \mathrm{O}_{3}$ were chosen as the model oxides for authentic atmospheric particles to further investigate the heterogeneous reaction of OCS in atmosphere. The reaction mechanism, final products and kinetics were studied with DRIFTS and ion chromatograph (IC). It should be helpful to further understanding the chemical cycles of OCS in the atmosphere.

\section{Experiment}

\subsection{Materials}

Carbonyl sulfide (OCS, $2 \%$, OCS/ $\mathrm{N}_{2}$ ) was supplied by Scott Specialty Gases Inc. and the content of $\mathrm{H}_{2} \mathrm{~S}$ and $\mathrm{SO}_{2}$ is lower than the detection limit of GC and MS. $\mathrm{CO}_{2}$ (99.995\%) was supplied by Haipu Gases Inc. in Beijing. $\mathrm{N}_{2}$ and $\mathrm{O}_{2}(99.999 \%)$ were from Beijing AP BEIFEN Gases Inc.

$\mathrm{SiO}_{2}, \mathrm{Al}_{2} \mathrm{O}_{3}, \mathrm{Fe}_{2} \mathrm{O}_{3}, \mathrm{CaO}, \mathrm{MgO}, \mathrm{ZnO}$, and $\mathrm{TiO}_{2}$ were chosen as model oxides for atmospheric particles in Beijing according to the X-ray fluorescent photometer (XRF) analysis results ${ }^{[15]}$. In order to obtain high signal to noise ratio $(\mathrm{S} / \mathrm{N})$ to better understand the reaction mechanism, the reaction of OCS on $\gamma-\mathrm{Al}_{2} \mathrm{O}_{3}$ with high specific surface area was investigated, while the surface area of other samples is close to that of authentic atmospheric particles. $\gamma-\mathrm{Al}_{2} \mathrm{O}_{3}$ and $\alpha-\mathrm{Al}_{2} \mathrm{O}_{3}$ were prepared through calcining $\mathrm{AlOOH}$ (Shandong Alumina Corpartion) at 873 and $1473 \mathrm{~K}$ for $3 \mathrm{~h}$, respectively. All of the other oxides are of analytic purity grade, such as $\mathrm{SiO}_{2}$ and $\mathrm{TiO}_{2}$ (Beijing Yili Fine Chemicals Co. Ltd), $\mathrm{Fe}_{2} \mathrm{O}_{3}$ (Beijing Nanshang Chemicals Factory), $\mathrm{CaO}$ and $\mathrm{ZnO}$ (Shantou Nongxi Chemicals Factory Guangdong), and $\mathrm{MgO}$ (Tianjin Hangu Haizhong Chemicals Factory).

\subsection{In situ DRIFTS experiment}

In situ DRIFTS spectra under reaction condition were recorded on a NEXUS 670 (Thermo Nicolet Instrument Corporation) FT-IR, equipped with an in situ diffuse reflection chamber and a high sensitivity mercury cadmium telluride (MCT) detector cooled by liquid $\mathrm{N}_{2}$. The temperature, pressure and concentration of reactant in reactor chamber can be controlled precisely by mass flow, temperature and vacuum controller system, respectively.

The concentration of OCS in simulated air $\left(79 \% \mathrm{~N}_{2}\right.$ and $21 \% \mathrm{O}_{2}$ ) was $500 \mathrm{ppm}$ and the total flow rate of feed gases was $100 \mathrm{~mL} \cdot \mathrm{min}^{-1}$ for all of the flow reaction systems. The temperature was kept at $298 \mathrm{~K}$. The sample ( $>200$ meshes) was pretreated in pure $\mathrm{O}_{2}$ at $573 \mathrm{~K}$ for $3 \mathrm{~h}$ to remove the surface organics, and then was exposed to simulated air at $298 \mathrm{~K}$ until a steady state was established for reference spectrum collection. The absorbance bands of gaseous water were also subtracted in reference spectrum. The infrared spectra for surface species were collected and analyzed by a computer with OMNIC 6.0 software in the range of $650-4000 \mathrm{~cm}^{-1}$. All the spectra reported here were recorded at a resolution of $4 \mathrm{~cm}^{-1}$ for 100 scans.

The kinetic study was performed in a closed system with in situ DRIFTS. The volume of reactor chamber is approximately $30 \mathrm{~cm}^{3}$. The reactant gas was introduced into reactor chamber for $5 \mathrm{~min}$ with the flow rate of 100 $\mathrm{mL} \cdot \mathrm{min}^{-1}$, and then the inlet and outlet were closed promptly. In order to investigate the surface species and final products, the experiments in flow system were performed to obtain high signal to noise ratio.

\subsection{Calibration curve of the gaseous OCS concen- tration}

A series of in situ DRIFTS spectra at a steady state were recorded at $298 \mathrm{~K}$ in flow system with various concentrations of OCS $(0-3000 \mathrm{ppm})$. The integrated areas of the absorption peak of gaseous OCS at 2071 and 2052 $\mathrm{cm}^{-1}$ have a linear correlation with the concentration of OCS gas ( $R$ is 0.9999). The concentration of gaseous 
OCS was determined by measuring the in situ DRIFTS spectra peak areas of gaseous OCS.

\subsection{Determining sulfate with ion chromatograph}

The yield of sulfate was determined using an ion chromatograph consisting of a pretreatment column (IonPac AG14A-SC, 4 mm, Dionex, CA), a separator (AS14A-SC, $4 \mathrm{~mm}$, Dionex, CA), a suppressor (ASRS-ULTRA, $4 \mathrm{~mm}$ Dionex, CA) and a pulse electronic chemical detector (Dionex, $\mathrm{CA}$ ). The analytic procedure was described as follows: $\mathrm{Na}_{2} \mathrm{CO}_{3} / \mathrm{NaHCO}_{3}$ $\left(3.5 \mathrm{mmol} \cdot \mathrm{L}^{-1} / 1 \mathrm{mmol} \cdot \mathrm{L}^{-1}\right)$ was used as eluting solution. The flow rate of eluting solution was $1.2 \mathrm{~mL} \cdot \mathrm{min}^{-1}$ and the injection volume was $25 \mu \mathrm{L}$. The concentration of sulfate has a linear correlation with integrated area of IC peak in the range of $1-40 \mathrm{mg} \cdot \mathrm{L}^{-1}$ ( $R$ is 0.9997$) .1 .0$ $\mathrm{g} \mathrm{SiO}_{2}$ sample pretreated at $573 \mathrm{~K}$ was exposed to 500 ppm OCS in simulated air with a flow rate of 100 $\mathrm{mL} \cdot \mathrm{min}^{-1}\left(W / F=0.18 \mathrm{~g} \cdot \mathrm{s} \cdot \mathrm{cm}^{-3}, G H S V=5000 \mathrm{~h}^{-1}\right)$ at $298 \mathrm{~K}$ for $3 \mathrm{~h}$. And then, the sulfate formed by heterogeneous reactions was supersonically extracted with $100.00 \mathrm{~mL}$ deionized water for $30 \mathrm{~min}$. The concentration of sulfate in filtrate with a $0.45-\mu \mathrm{m}$ filter was analyzed with ion chromatograph.

\subsection{Techniques of characterization}

Specific surface area was measured with a Micromeritics ASAP 2000 automatic equipment.

The X-ray powder diffraction pattern was collected from $10^{\circ}$ to $90^{\circ} 2 \theta$ on a $\mathrm{D} /$ max-RB automatic powder $\mathrm{X}$-ray diffractometer using $\mathrm{Cu} \mathrm{K} \alpha$ irradiation.

The total basicity of oxides was determined with $\mathrm{CO}_{2}$-temperature-programmed desorption $\left(\mathrm{CO}_{2}-\mathrm{TPD}\right)$. The TPD equipment consists of a temperature-programmed tube oven and a quadrupole mass spectrometer (QMS, Hiden HPRO 210). 0.1000-0.5000 g oxide samples were pretreated in $\mathrm{O}_{2}$ at $573 \mathrm{~K}$ for $3 \mathrm{~h}$, and then exposed to $99.995 \% \mathrm{CO}_{2}$ at $303 \mathrm{~K}$ for saturation (about $1 \mathrm{~h}$ ). Subsequently, the sample was purged with high purity $\mathrm{He}$ at $303 \mathrm{~K}$ to remove the physicaly adsorbed $\mathrm{CO}_{2}$ until the steady state was established for MS signal (about $1.5 \mathrm{~h}$ ). Temperature-programmed desorption was performed in a He gas flow of $30 \mathrm{~mL} \cdot \mathrm{min}^{-1}$ from 303 to $1123 \mathrm{~K}$ at $20 \mathrm{~K} \cdot \mathrm{min}^{-1}$. The total base content of the oxides was denoted with integrated area of QMS signal for desorbed $\mathrm{CO}_{2}$.

\section{Results and discussion}

\subsection{Characterization for samples}

The BET and XRD results are shown in Table 1. Except for $\gamma-\mathrm{Al}_{2} \mathrm{O}_{3}$, the specific surface area of all the other oxides is close to that of authentic atmospheric particles. As can be seen in Figure 1, all of these oxides show a good crystallinity. $\mathrm{CaO}$ sample contains a small amount of $\mathrm{Ca}(\mathrm{OH})_{2}$, which means it has a strong hygroscopicity. The crystal structure, components and the three main peaks are shown in Table 1.

Table 1 Specific surface area and components of mineral oxides

\begin{tabular}{|c|c|c|c|}
\hline Sample & $S_{\mathrm{BET}}\left(\mathrm{m}^{2} \cdot \mathrm{g}^{-1}\right)$ & Component & $2 \theta$ \\
\hline $\mathrm{SiO}_{2}$ & 4.80 & Quartz & $26.5,20.8,50.0$ \\
\hline $\mathrm{Fe}_{2} \mathrm{O}_{3}$ & 2.74 & hematite & $33.2,35.7,54.1$ \\
\hline $\mathrm{CaO}$ & 6.08 & Lime $\left(\mathrm{CaO}+\mathrm{Ca}(\mathrm{OH})_{2}\right)$ & $\begin{array}{l}37.3,53.8,32.2 \\
34.1,18.0,50.9\end{array}$ \\
\hline $\mathrm{MgO}$ & 14.59 & periclase & $42.9,62.3,78.6$ \\
\hline $\mathrm{ZnO}$ & 2.75 & spartalite & $36.2,31.7,34.3$ \\
\hline $\mathrm{TiO}_{2}$ & 12.74 & anatase & $25.3,48.0,37.7$ \\
\hline$\alpha-\mathrm{Al}_{2} \mathrm{O}_{3}$ & 12 & corundum & $35.0,43.0,57.0$ \\
\hline$\gamma-\mathrm{Al}_{2} \mathrm{O}_{3}$ & 277 & $\gamma-\mathrm{Al}_{2} \mathrm{O}_{3}$ & $13.8,28.2,38.6$ \\
\hline
\end{tabular}

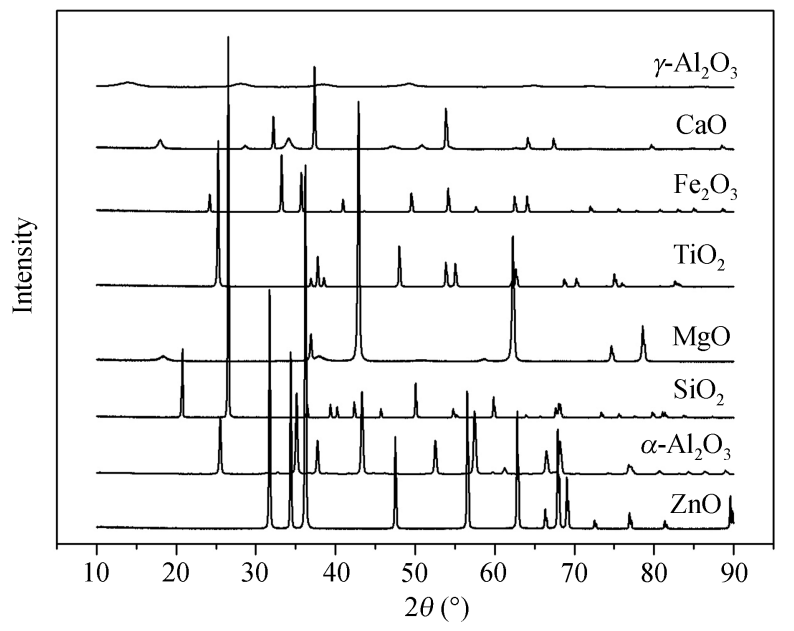

Figure 1 XRD patterns of the mineral oxides.

\subsection{Heterogeneous reactions of OCS on the oxides in flow system}

2.2.1 Heterogeneous reaction of OCS on $\mathrm{SiO}_{2}$. The in situ DRIFTS spectra for $\mathrm{SiO}_{2}$ at $298 \mathrm{~K}$ are shown in Figure 2 when exposed to 500 ppm OCS in air with 100 $\mathrm{mL} \cdot \mathrm{min}^{-1}$. The consumption of surface hydroxyl at $3709 \mathrm{~cm}^{-1[16,17]}$ was observed within $3 \mathrm{~h}$, accompanying with an increase of the intensity of hydrogen thiocarbonate $\left(\mathrm{HSCO}_{2}^{-}\right.$, the key intermediate) at 1574 $\mathrm{cm}^{-1[18,19]}$. However, it is incredible for surface sulfate 

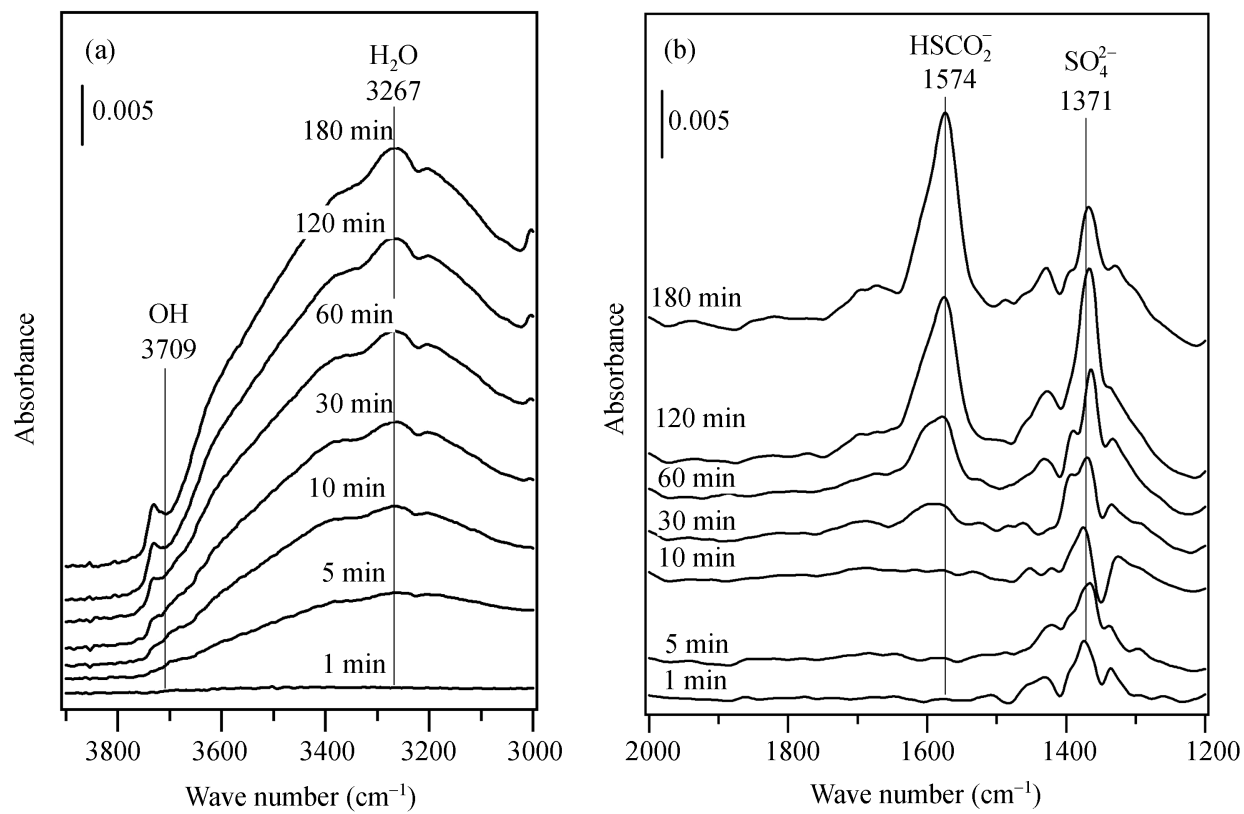

Figure 2 In situ DRIFTS spectra of $500 \mathrm{ppm}$ OCS in air on $\mathrm{SiO}_{2}$ at $298 \mathrm{~K}$. (a) In the range of $3000-3900 \mathrm{~cm}^{-1}$; (b) in the range of $1200-2000 \mathrm{~cm}^{-1}$.

species at $1371 \mathrm{~cm}^{-1}{ }^{[20-22]}$ because of the low signal to noise ratio due to the strong absorbance of $\mathrm{SiO}_{2}$ itself in the range of $1300-1400 \mathrm{~cm}^{-1}$. Therefore, ion chromatograph was used to affirm whether $\mathrm{SO}_{4}^{2-}$ was formed on $\mathrm{SiO}_{2}$. After $1.0 \mathrm{~g} \mathrm{SiO} 2$ was exposed to $500 \mathrm{ppm}$ OCS in air at $100 \mathrm{~mL} \cdot \mathrm{min}^{-1}$ for $3 \mathrm{~h}$, the surface sulfate increased by $0.093 \mathrm{mg} \cdot \mathrm{g}^{-1}$ when blank value was subtracted. It suggests that heterogeneous reaction takes place on $\mathrm{SiO}_{2}$ and sulfate is one of the final products.

2.2.2 Heterogeneous reaction of OCS on $\mathrm{CaO}$. As shown in Figure 3, the dominant surface species include bicarbonate $\left(\mathrm{HCO}_{3}^{-}, 1670\right.$ and $\left.1637 \mathrm{~cm}^{-1}\right)$ and sulfate $\left(\mathrm{SO}_{4}^{2-}, 1348 \mathrm{~cm}^{-1}\right)$ for heterogeneous reaction of OCS on $\mathrm{CaO}$. Carbonate $\left(1529 \text { and } 850 \mathrm{~cm}^{-1}\right)^{[23,24]}$ and sulfite $\left(1085 \text { and } 945 \mathrm{~cm}^{-1}\right)^{[22,25]}$ were also observed. The intensity of these products increases with increasing exposure time. The weak bands at 1902 and $1882 \mathrm{~cm}^{-1}$ were assigned to physically adsorbed $\mathrm{OCS}^{[18,19]}$. It should be noted that the decrease of surface hydroxyl was not clear (shown in Figure 3(a)), while the increase of surface products is very obvious. This contradiction can be ascribed to the adsorption of water to compensate the consumed hydroxyl, which was confirmed by the increase of bands at 3427 and $3143 \mathrm{~cm}^{-1}$ of water in intensity. Furthermore, the strong hygroscopic ability for $\mathrm{CaO}$ was also approved by the presence of small amount of $\mathrm{Ca}(\mathrm{OH})_{2}$ identified by XRD.
The heterogeneous reactions of OCS on $\mathrm{MgO}$ and $\mathrm{ZnO}$ resemble that on $\mathrm{CaO}$. Surface species including $\mathrm{HSCO}_{2}^{-}, \mathrm{HCO}_{3}^{-}, \mathrm{CO}_{3}^{2-}, \mathrm{HSO}_{3}^{-}, \mathrm{SO}_{3}^{2-}$ and $\mathrm{SO}_{4}^{2-}$ were observed. The strong hygroscopic ability of $\mathrm{ZnO}$ also leads to little consumption of surface hydroxyl species as shown Figure 3.

2.2.3 Heterogeneous reaction of $\mathrm{OCS}$ on $\mathrm{TiO}_{2}$. Figure 4 shows the in situ DRIFTS spectra of heterogeneous reaction of OCS on $\mathrm{TiO}_{2}$. The distinct decrease of surface hydroxyl (3736 and $3670 \mathrm{~cm}^{-1}$ ) and the increase of the key intermediate, $\mathrm{HSCO}_{2}^{-}\left(1540 \mathrm{~cm}^{-1}\right)$, were observed, whereas the intensity of surface $\mathrm{HCO}_{3}^{-}$ $\left(1466 \mathrm{~cm}^{-1}\right)$ and $\mathrm{SO}_{4}^{2-}$ (1389 and $\left.1146 \mathrm{~cm}^{-1}\right)$ did not increase obviously. The formation of $\mathrm{HSCO}_{2}^{-}$accompanying with consumption of surface hydroxyl suggests that the heterogeneous reaction on $\mathrm{TiO}_{2}$ occurred, while the further oxidation of $\mathrm{HSCO}_{2}^{-}$to form $\mathrm{HCO}_{3}^{-}$and $\mathrm{SO}_{4}^{2-}$ was very slow.

2.2.4 Heterogeneous reaction of OCS on $\mathrm{Fe}_{2} \mathrm{O}_{3}$. The heterogeneous reactivity of OCS on $\mathrm{Fe}_{2} \mathrm{O}_{3}$ is very weak as shown in Figure 5. However, the decrease of surface hydroxyl at 3712 and $3658 \mathrm{~cm}^{-1}$ and the increase of hydrogen thiocarbonate at $1541 \mathrm{~cm}^{-1}$ demonstrate that the reaction occurred. The peaks of $\mathrm{HCO}_{3}^{-}$(1649 and 1396 $\left.\mathrm{cm}^{-1}\right), \mathrm{SO}_{4}^{2-}\left(1367\right.$ and $\left.1128 \mathrm{~cm}^{-1}\right), \mathrm{HSO}_{3}^{-}(1246$ 

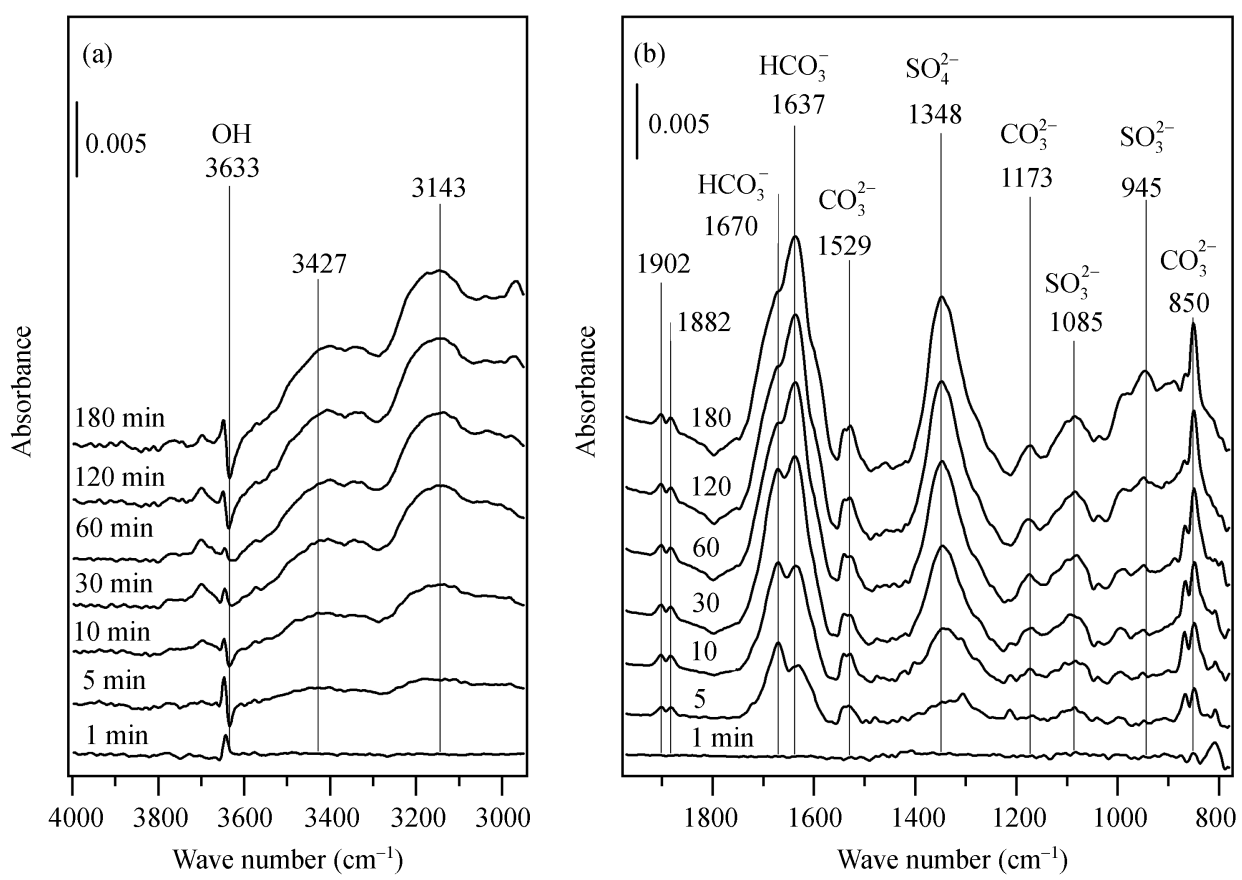

Figure 3 In situ DRIFTS spectra of 500 ppm OCS in air on CaO at $298 \mathrm{~K}$. (a) In the range of $2950-4000 \mathrm{~cm}^{-1}$; (b) in the range of $800-1950 \mathrm{~cm}^{-1}$.
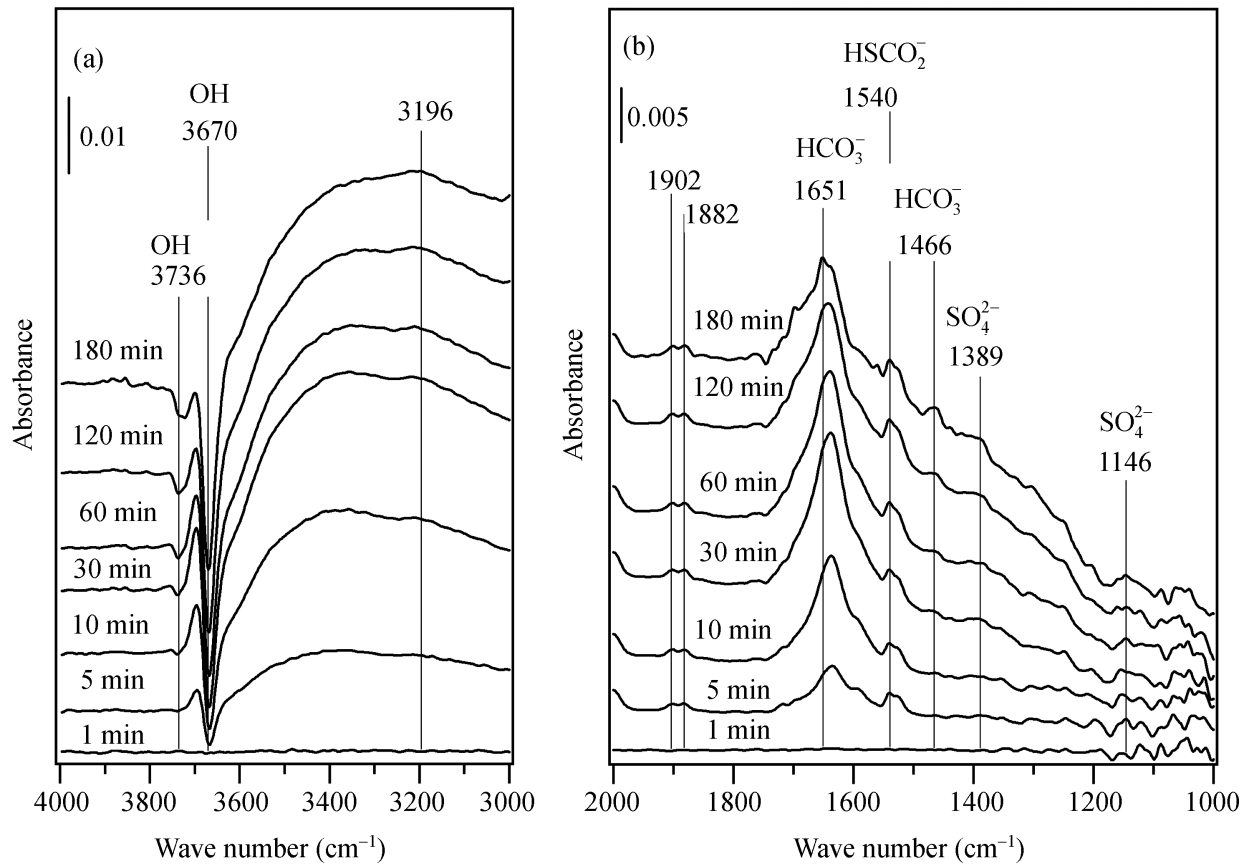

Figure 4 In situ DRIFTS spectra of $500 \mathrm{ppm} \mathrm{OCS} \mathrm{in} \mathrm{air} \mathrm{on} \mathrm{TiO}_{2}$ at $298 \mathrm{~K}$. (a) In the range of $3000-4000 \mathrm{~cm}^{-1}$; (b) in the range of $1000-2000 \mathrm{~cm}^{-1}$.

$\left.\mathrm{cm}^{-1}\right)$ and $\mathrm{SO}_{3}^{2-}\left(1038 \mathrm{~cm}^{-1}\right)$ also increased slowly with increasing exposure time.

2.2.5 Comparison of heterogeneous reactions for OCS on different oxides. The products for heterogeneous reactions of OCS on the above oxides are enumerated in Table 2. Obviously, the heterogeneous reactions could take place on all of these oxides at ambient temperature.
The consumption of surface hydroxyl and the formation of sulfate were observed. It should be noted that the frequency for consumed hydroxyl on these oxides is nearby $3700 \mathrm{~cm}^{-1}$, which belongs to basic hydroxyl ${ }^{[26]}$. The key intermediate, surface $\mathrm{HSCO}_{2}^{-}$, was observed on $\mathrm{TiO}_{2}, \mathrm{Fe}_{2} \mathrm{O}_{3}$ and $\mathrm{SiO}_{2}$ due to the weak reactivity. Sulfites $\left(\mathrm{HSO}_{3}^{-}\right.$and $\mathrm{SO}_{3}^{2-}$ ) were also observed on $\mathrm{MgO}$ 

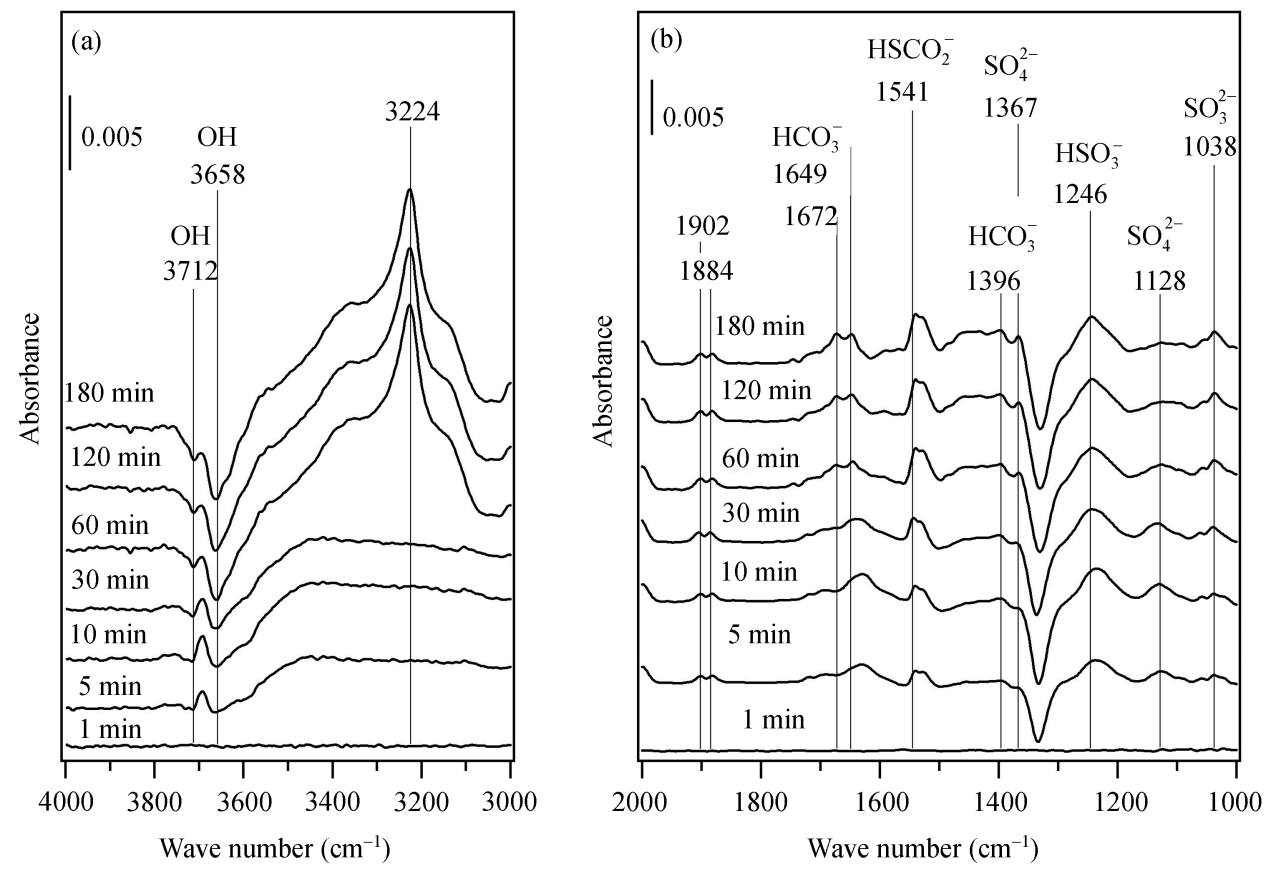

Figure 5 In situ DRIFTS spectra of 500 ppm OCS in air on $\mathrm{Fe}_{2} \mathrm{O}_{3}$ at $298 \mathrm{~K}$. (a) In the range of $3000-4000 \mathrm{~cm}^{-1}$; (b) in the range of $1000-2000 \mathrm{~cm}^{-1}$.

Table 2 Products for heterogeneous reactions of OCS on model oxides

\begin{tabular}{|c|c|c|c|c|c|c|c|c|}
\hline Oxide & Physical adsorbed OCS & $\mathrm{HS}^{-}$ & $\mathrm{HSCO}_{2}^{-}$ & $\mathrm{HSO}_{3}^{-}$ & $\mathrm{SO}_{3}^{2-}$ & $\mathrm{SO}_{4}^{2-}$ & $\mathrm{HCO}_{3}^{-}$ & $\mathrm{CO}_{3}^{2-}$ \\
\hline $\mathrm{SiO}_{2}$ & $x$ & $x$ & $\sqrt{ }$ & $\times$ & $\times$ & $\sqrt{ }$ & $\times$ & $\times$ \\
\hline $\mathrm{MgO}$ & $x$ & $\sqrt{ }$ & $\sqrt{ }$ & $\sqrt{ }$ & $\sqrt{ }$ & $\sqrt{ }$ & $\sqrt{ }$ & $\sqrt{ }$ \\
\hline $\mathrm{CaO}$ & $\sqrt{ }$ & $x$ & $x$ & $x$ & $\sqrt{ }$ & $\sqrt{ }$ & $\sqrt{ }$ & $\sqrt{ }$ \\
\hline $\mathrm{ZnO}$ & $\sqrt{ }$ & $x$ & $x$ & $x$ & $\sqrt{ }$ & $\sqrt{ }$ & $\sqrt{ }$ & $\sqrt{ }$ \\
\hline $\mathrm{TiO}_{2}$ & $\sqrt{ }$ & $\times$ & $\sqrt{ }$ & $x$ & $x$ & $\sqrt{ }$ & $\sqrt{ }$ & $x$ \\
\hline $\mathrm{Fe}_{2} \mathrm{O}_{3}$ & $\sqrt{ }$ & $\times$ & $\sqrt{ }$ & $\sqrt{ }$ & $\sqrt{ }$ & $\sqrt{ }$ & $\sqrt{ }$ & $x$ \\
\hline $\mathrm{Al}_{2} \mathrm{O}_{3}$ & $x$ & $x$ & $\sqrt{ }$ & $\sqrt{ }$ & $x$ & $\sqrt{ }$ & $\sqrt{ }$ & $x$ \\
\hline
\end{tabular}

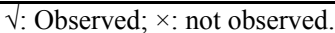

and $\mathrm{Fe}_{2} \mathrm{O}_{3}$. Therefore, it can be deduced that the reaction mechanism of OCS on these oxides should be the same as that on $\mathrm{Al}_{2} \mathrm{O}_{3}$ because there are the same intermediate and final products. Additionally, the reactivity for OCS on these oxides is in the sequence as follows: $\mathrm{CaO}, \mathrm{MgO}$ $>\mathrm{ZnO}, \mathrm{TiO}_{2}>\mathrm{Fe}_{2} \mathrm{O}_{3}>\mathrm{SiO}_{2}$, which is consistent with the basicity of oxides. The reaction of OCS on $\mathrm{CaO}$ is very fast, while little surface hydroxyl has been consumed. It can be ascribed to the strong hygroscopic ability of $\mathrm{CaO}$ and the strong basicity.

\subsection{Kinetics of heterogeneous reactions for OCS on model oxides}

As discussed in the above section, there is a distinct discrepancy for heterogeneous reactivity of OCS on these oxides. Therefore, the kinetics of heterogeneous reactions of OCS on different oxides in close system was studied in particular. Figure 6 shows the change of con- centration of gaseous OCS with time over different oxides. After the preoxidized oxide samples were exposed to $500 \mathrm{ppm}$ of OCS in air at $100 \mathrm{~mL} \cdot \mathrm{min}^{-1}$ for $5 \mathrm{~min}$, the inlet and outlet of the reactor chamber were closed at the same time, and then the gaseous concentration of OCS was measured with in situ DRIFTS online.

Strictly speaking, heterogeneous uptake including adsorption and heterogeneous reaction leads to the loss of gaseous OCS. However, it is simply described as heterogeneous reaction in the following section. Figure 6 shows that the concentration of gaseous OCS in reactor chamber decreased quickly with time over $\mathrm{CaO}, \gamma-\mathrm{Al}_{2} \mathrm{O}_{3}$ and $\mathrm{MgO}$ in a closed system. The conversion of OCS is greater than $90 \%$ within $1 \mathrm{~h}$ for these three oxides. The reaction rate of OCS on $\mathrm{TiO}_{2}, \mathrm{ZnO}$ and $\mathrm{Fe}_{2} \mathrm{O}_{3}$ is much slower than that on the former three oxides, while the consumption of OCS is still perceptible. However, the 
conversion of OCS on $\mathrm{SiO}_{2}$ and $\alpha-\mathrm{Al}_{2} \mathrm{O}_{3}$ is almost the same as that on background (gold mirror) which means the weak reactivity.

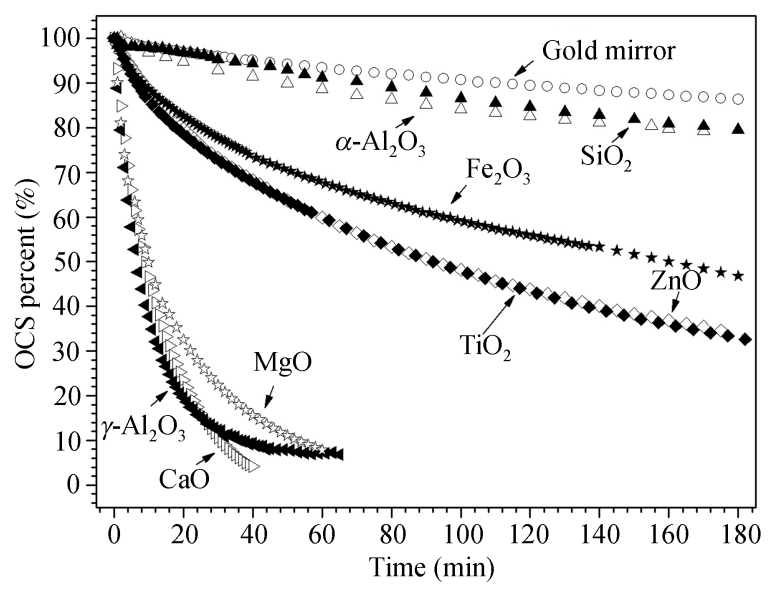

Figure 6 Changes of OCS concentration with time in a closed system at $298 \mathrm{~K}$.

The changes of OCS on these oxide accord with quasi-first order reaction within $1 \mathrm{~h}$. The kinetic parameters are shown in Table 3. The observed reaction rate follows: $\gamma-\mathrm{Al}_{2} \mathrm{O}_{3} \approx \mathrm{CaO}>\mathrm{MgO}>\mathrm{TiO}_{2} \approx \mathrm{ZnO}>\mathrm{Fe}_{2} \mathrm{O}_{3}>$ $\alpha-\mathrm{Al}_{2} \mathrm{O}_{3} \approx \mathrm{SiO}_{2}$. It should be noted that there exists large gapes between specific surface areas of different oxide samples, which may greatly affect the heterogeneous reaction. For example, it is $277 \mathrm{~m}^{2} \cdot \mathrm{g}^{-1}$ for $\gamma-\mathrm{Al}_{2} \mathrm{O}_{3}$ while it is only $2.75 \mathrm{~m}^{2} \cdot \mathrm{g}^{-1}$ for $\mathrm{ZnO}$ and $\mathrm{Fe}_{2} \mathrm{O}_{3}$. And the observed reaction rate of OCS on $\gamma-\mathrm{Al}_{2} \mathrm{O}_{3}$ is about 10 times that on $\mathrm{ZnO}$ and $\mathrm{Fe}_{2} \mathrm{O}_{3}$. However, the specific surface area of $\gamma-\mathrm{Al}_{2} \mathrm{O}_{3}$ is 50 times that of $\mathrm{CaO}$, while the observed reaction rate on them is almost equivalent. This means some other factors, such as content of surface hydroxyl and surface basicity of oxides, etc. should also be taken into account. In Table 3, it is observed that the stronger the basicity of oxides, the larger the observed reaction rate. For example, the specific surface area of $\mathrm{MgO}$ is the same as that of $\mathrm{TiO}_{2}$, so do for $\mathrm{ZnO}$ and $\mathrm{Fe}_{2} \mathrm{O}_{3}$, whereas the reaction rate of OCS on $\mathrm{MgO}$ and $\mathrm{ZnO}$ is greater than that on $\mathrm{TiO}_{2}$ and $\mathrm{Fe}_{2} \mathrm{O}_{3}$, respectively.

He et al. ${ }^{[27]}$ have reported that the first step for heterogeneous reaction of OCS on $\mathrm{Al}_{2} \mathrm{O}_{3}$ is the attack of carbon atom with positive charge $\left(\delta^{+}=0.11\right)^{[21]}$ by surface hydroxyl. Therefore, the reaction rates should be affected by the basicity or nucleophilicity of surface hydroxyl on oxides. The basicity and total base content were measured by $\mathrm{CO}_{2}$-TPD to understand the relationship between the reactivities of OCS on oxides and the basicities of oxides. As shown in Figure 7, the desorption temperature of $\mathrm{CO}_{2}$ for different oxides follows the order of $\mathrm{CaO}>\mathrm{MgO}>\gamma-\mathrm{Al}_{2} \mathrm{O}_{3}>\mathrm{ZnO}, \mathrm{TiO}_{2}, \mathrm{Fe}_{2} \mathrm{O}_{3}$, $\mathrm{SiO}_{2}$, which is in accordance with the basicity and reaction activity approximately. It suggests that the heterogeneous reactions of OCS on these oxides belong to base-catalyzed reaction and can be explained by Brönsted rule ${ }^{[28]}$. Figure 8 shows the total base content of per gram oxide sample representing the number of base site on oxide surface. The order of base site number on these oxides is: $\mathrm{CaO}>\mathrm{MgO}>\gamma-\mathrm{Al}_{2} \mathrm{O}_{3}>\mathrm{ZnO}>\mathrm{TiO}_{2}>\mathrm{Fe}_{2} \mathrm{O}_{3}$

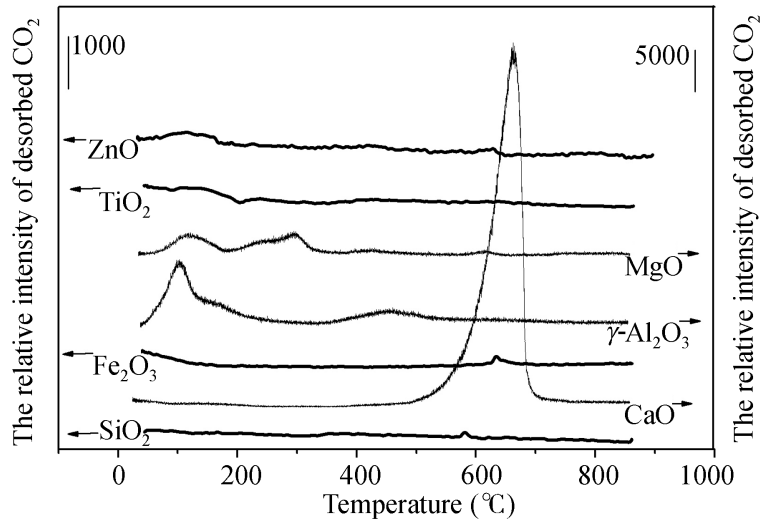

Figure $7 \mathrm{CO}_{2}$-TPD spectra for oxides after saturated $\mathrm{CO}_{2}$ adsorption.

Table 3 Reaction rates for OCS on different oxides

\begin{tabular}{|c|c|c|c|c|c|c|c|}
\hline Oxide & $\begin{array}{l}\text { Specific area } \\
\left(\mathrm{m}^{2} \cdot \mathrm{g}^{-1}\right)\end{array}$ & $\begin{array}{l}\text { Observed reaction } \\
\text { rate }\left(\mathrm{s}^{-1}\right)\end{array}$ & $\begin{array}{l}\text { Half time } \\
\quad(\min )\end{array}$ & $\begin{array}{l}\text { Correlation } \\
\text { coefficient }\end{array}$ & $\begin{array}{c}\text { Conversion \% } \\
(30 \mathrm{~min})\end{array}$ & $\begin{array}{c}\text { Conversion \% } \\
(3 \mathrm{~h})\end{array}$ & $\begin{array}{c}\text { Specific reaction rate } \\
\left(\mathrm{g} \cdot \mathrm{s}^{-1} \cdot \mathrm{m}^{-2}\right)\end{array}$ \\
\hline Gold mirror & - & $2.0 \times 10^{-5}$ & - & - & 3.6 & 13.7 & - \\
\hline $\mathrm{CaO}$ & 6.10 & $1.2 \times 10^{-3}$ & 9.6 & 0.9994 & 89.4 & - & $2.0 \times 10^{-4}$ \\
\hline $\mathrm{MgO}$ & 14.59 & $8.0 \times 10^{-4}$ & 14.4 & 0.9969 & 77.6 & - & $5.5 \times 10^{-5}$ \\
\hline $\mathrm{SiO}_{2}$ & 4.80 & $4.0 \times 10^{-5}$ & 289 & 0.9968 & 4.7 & 21.6 & $8.3 \times 10^{-5}$ \\
\hline $\mathrm{ZnO}$ & 2.75 & $2.0 \times 10^{-4}$ & 57.8 & 0.9936 & 27.8 & 67.4 & $3.3 \times 10^{-6}$ \\
\hline $\mathrm{Fe}_{2} \mathrm{O}_{3}$ & 2.74 & $1.0 \times 10^{-4}$ & 116 & 0.9475 & 22.2 & 53.2 & $3.7 \times 10^{-5}$ \\
\hline $\mathrm{TiO}_{2}$ & 12.74 & $2.0 \times 10^{-4}$ & 57.8 & 0.9907 & 26.8 & 65.4 & $1.6 \times 10^{-5}$ \\
\hline$\alpha-\mathrm{Al}_{2} \mathrm{O}_{3}$ & 12.0 & $5.0 \times 10^{-5}$ & 231 & 0.9892 & 7.2 & 22.0 & $4.2 \times 10^{-6}$ \\
\hline$\gamma-\mathrm{Al}_{2} \mathrm{O}_{3}$ & 277 & $1.3 \times 10^{-3}$ & 8.9 & 0.9991 & 87.7 & - & $4.7 \times 10^{-6}$ \\
\hline
\end{tabular}




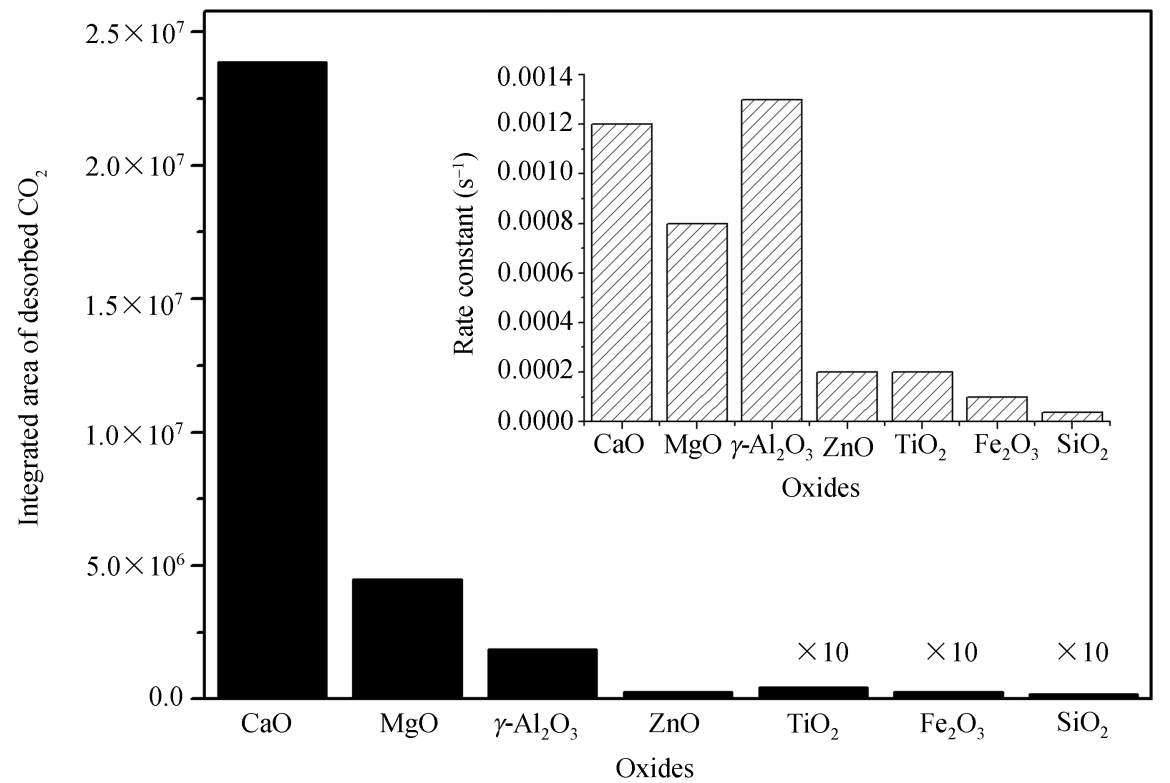

Figure 8 Content of surface basicity of oxides. Insert graph indicates the reaction rate constants of OCS on corresponding oxides.

$>\mathrm{SiO}_{2}$. And that of $\mathrm{CaO}$ is much greater than the other oxides. Therefore, the high reactivity of OCS on $\mathrm{CaO}$ can be ascribed to its high base content although a little surface hydroxyl is consumed in reaction (Figure 3(a)). The insert graph in Figure 8 also shows the observed rate constants of OCS on different oxides. Obviously, besides $\gamma-\mathrm{Al}_{2} \mathrm{O}_{3}$, the reaction activity sequence resembles the base content of oxides. When treated with Brönsted rule, the logarithm of the catalysis factor, $\log k_{\mathrm{b}}$ $\left(k_{\mathrm{b}}=k / B\right.$, the ratio of observed rate constant and total base content per gram oxide), is linearly correlated to $p K_{\mathrm{b}}$ of oxides for $\mathrm{CaO}, \mathrm{MgO}$ and $\gamma-\mathrm{Al}_{2} \mathrm{O}_{3}{ }^{[21]}$ (the $p K_{\mathrm{b}}$ value for other oxides cannot be obtained). The fitting result is shown in Figure 9 and the linearly dependent coefficient is 0.9947 . This means the reaction rate of OCS on oxides is determined by the basicity of oxides and the reaction mechanism on these oxides should be similar to that on $\mathrm{Al}_{2} \mathrm{O}_{3}$.

It should be noted that the catalysis or absorption of OCS by interior surface of reactor chamber cannot be avoided in our experiment. On the other hand, it is difficult to obtain the initial reaction rate because the oxide samples must be exposed to reactant gas in flow system for about $5 \mathrm{~min}$ to reach a certain concentration. Therefore, it is necessary to improve experimental method to decrease system error and properly choose oxide samples with similar specific surface area to better understand the reaction activity of OCS on mineral oxides.

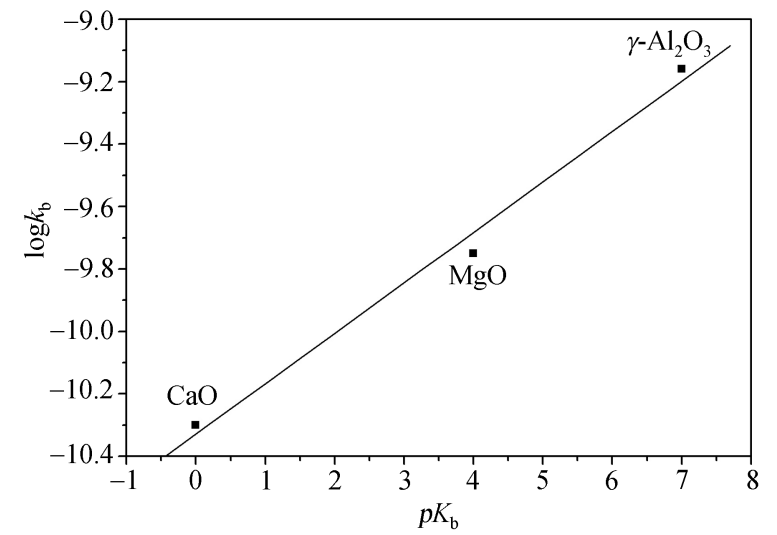

Figure 9 Correlation between catalysis coefficient and basicity of oxides.

\section{Conclusion}

This study reveals that OCS can be oxidized on mineral oxides in air to produce surface $\mathrm{SO}_{4}^{2-}$ and gaseous $\mathrm{CO}_{2}$ at ambient temperature. The surface $\mathrm{HSCO}_{2}^{-}$was identified to be a key intermediate on $\mathrm{TiO}_{2}, \mathrm{Fe}_{2} \mathrm{O}_{3}$ and $\mathrm{SiO}_{2}$. The intermediate product, surface $\mathrm{HSO}_{3}^{-}$, was also observed on $\mathrm{MgO}$ and $\mathrm{Fe}_{2} \mathrm{O}_{3}$. The reaction mechanism of OCS on these mineral oxides is the same as that on $\mathrm{Al}_{2} \mathrm{O}_{3}$ and authentic atmospheric particles reported in our previous work. The reaction activity of OCS on these oxides is in the sequence of $\gamma-\mathrm{Al}_{2} \mathrm{O}_{3} \approx \mathrm{CaO}>\mathrm{MgO}$ $>\mathrm{TiO}_{2} \approx \mathrm{ZnO}>\mathrm{Fe}_{2} \mathrm{O}_{3}>\alpha-\mathrm{Al}_{2} \mathrm{O}_{3}>\mathrm{SiO}_{2}$. It is found that the reactivity was affected by the surface area and surface basicity of oxides. As for the oxides with equivalent 
surface area, the reaction activity is determined by basicity. Therefore, the basic components of authentic atmospheric particles may contribute to the heterogeneous oxidation of OCS in the atmosphere. The heterogeneous reactions of OCS on mineral oxides should be considered in model study. Of course, in order to obtain high signal to noise ratio, 500 ppm of OCS was used in ex-

1 Turco R P, Whitten R C, Toon O B, et al. Stratospheric aerosols and climate. Nature, 1980, 283: 283-285

2 Andreae M O, Crutzen P J. Atmospheric aerosols: Biogeochemical sources and role in atmospheric chemistry. Science, 1997, 276: $1052-1058$

3 Crutzen P J. The possible importance of CSO for the sulfate layer of the stratosphere. Geophys Res Lett, 1976, 3: 73-76

4 Watts S F. The mass budgets of carbonyl sulfide, dimethyl sulfide, carbon disulfide and hydrogen sulfide. Atmos Environ, 2000, 34(5): $761-779$

5 Yang W X, Mu Y J, Liu Y, et al. Ozone depletion rate on ice surface at low temperature. Chin Sci Bull, 1996, 41(4): 343-345

6 Mu Y J, Liu Y, Yang W X. The stickincoefficients of ozone on ice and doped ice. Acta Sci Cirtumstan (in Chinese), 2000, 20(4): 410-414

7 Ravishankara A R. Heterogeneous and multiphase chemistry in the troposphere. Science, 1997, 276: 1058-1064

8 Ding J, Zhu T. Heterogeneous reactions on the surface of fine particles in atmosphere. Chin Sci Bull, 2003, 48(21): 2267-2276

9 Wang L, Zhang F, Cheng J M. Heterogeneous catalysis reaction between carbon disulfide and atmospheric particles. Chem J Chin Univ (in Chinese), 2002, 23(5): 866-870

10 Lin G Z, Mao S S, Wang Q G. Powder X-ray diffraction analysis of atmospheric particles in Beijing. Acta Sci Circumstan (in Chinese), 1983, 3(4): 311-318

11 Zhang Z, Friedlander S K. A comparative study of chemical databases for fine particle Chinese aerosols. Environ Sci Technol, 2000, 34(22): 4687-4694

12 Gordon E B J. How minerals react with water. Science, 2001, 294: $67-70$

13 Tang X Y. Atmospheric Envrionmental Chemistry (in Chinese). Beijing: Higher Education Press, 1990. 182

14 Wu H B, Wang X, Cheng J M, et al. Mechanism of the heterogeneous reaction of carbonyl sulfide with typical components of atmospheric aerosol. Chin Sci Bull, 2004, 49(12): 1231-1235

15 He H, Liu J F, Mu Y J, et al. Heterogeneous oxidation of carbonyl sulfide on atmospheric particles and alumina. Environ Sci Technol, 2005, 39(24): 9637-9642 periment that is much higher than that in the real atmosphere. However, the reaction mechanism under experimental condition is still reasonable and credible. Although the kinetic parameters cannot be used in model study directly, the general law for reaction rate and basicity is helpful to better understanding the heterogeneous reactions of OCS on atmospheric particles.

16 Peri J B, Hannan R B. Surface hydroxyl groups on $\gamma$-alumina. J Phys Chem, 1960, 64(10): 1526-1530

17 Ballinger T H, Yates J J T. IR spectroscopic detection of Lewis acid sites on alumina using adsorbed carbon monoxide: Correlation with aluminum-hydroxyl group removal. Langmuir, 1991, 7(12): $3041-3045$

18 Lavalley J C, Travert J, Chevreau T, et al. Infrared study of coadsorption of $\mathrm{H}_{2} \mathrm{~S}$ and $\mathrm{CO}_{2}$ on $\gamma$-alumina. J Chem Soc Chem Comm, 1979, (4): 146-148

19 Hoggan P E, Aboulayt A, Pieplu A, et al. Mechanism of COS hydrolysis on alumina. J Catal, 1994, 149(2): 300-306

20 Saur O, Bensitel M, Mohammed Saad A B, et al. The structure and stability of sulfated alumina and titania. J Catal, 1986, 99(1): $104-110$

21 Lavalley J C. Infrared spectrometric studies of the surface basicity of metal oxides and zeolites using adsorbed probe molecules. Catal Today, 1996, 27(3-4): 377-401

22 Goodman A L, Li P, Usher C R, et al. Heterogeneous uptake of sulfur dioxide on aluminum and magnesium oxide particles. J Phys Chem A, 2001, 105(25): 6109-6120

23 Amenomiya Y, Morikawa Y, Pleizier G. Infrared spectroscopy of $\mathrm{C}^{18} \mathrm{O}_{2}$ on alumina. J Catal, 1977, 46(3): 431-433

24 Rege S U, Yang R T. A novel FTIR method for studying mixed gas adsorption at low concentrations: $\mathrm{H}_{2} \mathrm{O}$ and $\mathrm{CO}_{2}$ on $\mathrm{NaX}$ zeolite and $\gamma$-alumina. Chem Eng Sci, 2001, 56(12): 3781-3796

25 Chang C C. Infrared studies of $\mathrm{SO}_{2}$ on $\gamma$-alumina. J Catal, 1978, 53(3): 374-385

26 Turek A M, Wachs I E, DeCanio E. Acidic properties of aluminasupported metal oxide catalysts: An infrared spectroscopy study. J Phys Chem, 1992, 96(12): 5000—5007

27 Liu J F, Yu Y B, Mu Y J, et al. Mechanism of heterogeneous oxidation of carbonyl sulfide on $\mathrm{Al}_{2} \mathrm{O}_{3}$ : An in situ diffuse reflectance infrared Fourier transform spectroscopy investigation. J Phys Chem B, 2006, 110: $3225-3230$

28 Wu Y. Catalysis Chemistry (in Chinese). Vol.1. Beijing: Science Press, 2000. 188 